\title{
Electronic Agriculture Resources and Agriculture Industrialization Support Information Service Platform Structure and Implementation
}

\author{
Zhao Xiaoming \\ Ningxia Academy of Agriculture and Forestry Sciences, \\ Yinchuan,750002, P.R. China \\ Zhaoxm9@tom. com
}

\begin{abstract}
Agriculture resources and agriculture industrialization support information service platform is an important part of Agriculture affair support platform of west part national area of P. R. China, a key projects in the National Science \& Technology Pillar Program in the Eleventh Five-year Plan Period. The system is designed as a 3 layers structure. Database support subsystem is the base layer. The middle layer contains GIS model and general reuse models; the upper layer is affair process interface and the entire manager interface. Consider of the country situation of China west, nature village is setup as a information manage unit. Famers in the village act as the registered user. Other government layer monitor the system running and distribute their index independently, system managed in the province layer. Software implement under Microsoft Windows server 2003, running as a Server/Browser style.
\end{abstract}

\section{Introduction}

The west of China is a territory living many different minorities; agriculture is the bases of economy in this area. Agriculture developments depend on agriculture industrialization and modern technique application, such as IT. Information system will support agriculture technique spread and the product process management. With growth of e-commerce, agriculture products selling on-line became an effective way for famer and Agriculture Company. Information of agriculture and rural could manage and spread thought the web.

People in Ningxia recognized the importance of agriculture and rural information system, government spread internet to each village during 2007-2008. In order to support the progress of informatization of minorities living area, serial key projects were arranged in the National Science \& Technology Pillar Program. Those projects help agriculture of minorities living area transmits from tradition to modern.

Building an agriculture resources and agriculture industrialization support information service platform for west of China based on Ningxia Hui Autonomous Region and setup a test platform in Yinchuan is a part of work in those key projects. This paper describes the software structure design and implementation. 


\section{Software System Design}

\subsection{The Goal of Software System Design}

Villages are the base units of agriculture produce organizer and farmer's life circle in Chinese rural area. Agriculture industrialization developed on traditional village and enriches the farmers. Electronic Agriculture Resources and agriculture Industrialization Support information service Platform (eARISP) designed as a village oriented, and farmers participated information system, which provide agriculture products price and selling information system, village affair management system, and industrial chain support system, agriculture resources development service system.

A province is an agriculture management domain; and it is also an information service domain. Province data center setups in province agriculture department. The middle government units, town and county act as manager who release information and do data statistic. Villages are the base units have its web page; farmers are end user of system.

The design innovation is Province-village model. eARISP is not a e-government system, it is an agriculture industrialization support information service platform. Farmer needs freedom to learn technique, manage their field products, get and put information. We design town and county as a limited manager user to reduce manage layer, create a free virtual society server to agriculture industrialization development.

eARISP is also act as an agriculture technique query system, provide technique graph and document, online agriculture expert interview and question answer. An agriculture science and technique knowledgebase were build as an encyclopedia for end user. Agriculture experts registered as adviser user without administration boundary, who was authorized to edit the content of knowledgebase and answer the questions provided by the end users.

Super user work in province data centre manages whole system. Figure 1 shows users role arrangement and relationships.

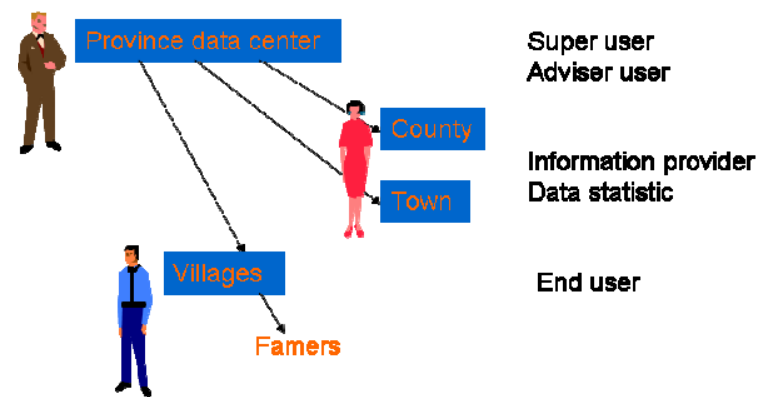

Fig. 1. Users role arrangement and relationships

\subsection{The Division of System Function}

System function divided into several groups. Each group functioned as an aspect of application. 


\subsubsection{Village Affair Management System}

Village affair manage system focus on agriculture product produce, organize farmers as member, share agriculture information and put their products information on the web. Traditional Chinese village member have stronger traditional value, whole village honor concerned to each member which is the bases of e-selling credit. Village affair manage system does not concern with political issues which integrate in another system of the project.

\subsubsection{Industrialization Chain Support System}

Agriculture industrialization chain are including about agriculture products process from land, seeding to products selling and concerned agriculture material providing. How does information system support agriculture industrialization chain? Experts have different viewpoints. According to current status of agriculture and rural in China west, technique information obtain and products selling are two most important factors in agriculture industrialization chain building. An encyclopedia like agriculture technique system included as a part of this system. Agriculture experts in a province range are organized as online adviser, their technique answer will add to correspond item in technique encyclopedia. An agriculture products information system was designed to support products selling on line.

\subsubsection{Rural Area Planning Management System}

Rural planning is a great problem during China new country building process. The goal of manage system in eARISP will provide guideline or models suggested by government. It works as an interview platform. GIS data of rural collected and store in database, user query and display planning graph by WebGIS. First time we image rural planning management as $3 \mathrm{D}$ environment and people can design a village and its facilities, and virtual walk through. But rural area is too large to build 3D data set to describe whole area. So first step, we design rural planning management by support of WebGis. 3D environment will build in future.

\subsubsection{Agriculture Resource Development Management System}

At the view of the whole management domain, agriculture resource show and manage for different user with different authority.

District and its basic information.

Crop distribution: species, area, field product etc.

Environment resource data.

Land use information.

Commercial information and data.

Policy, tax.

\subsubsection{Database Management}

Database in eARISP may include several subjects:

Agriculture technique knowledge base

Agriculture commercial database

Agriculture planning information and GIS

Agriculture product database

Statistical database

User and system management database 
Database manages all data used in system. Data used in the system include user data, geographic data, agriculture knowledge, and some spatial data. MySQL is used in the test platform.

\section{Software Structure}

Well-designed software structure will help developer integrate different software models. eARISP was designed as a structure software in order to use software components, such as GIS, database system, transaction process system and other common middle ware designed by company.

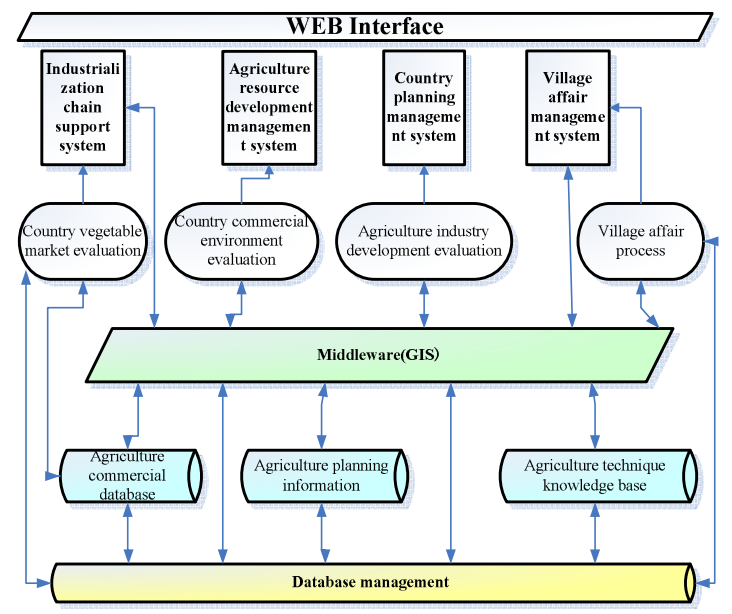

Fig. 2. Software structure

\subsection{Agriculture Industrialization Resource Modeling}

Agriculture resource includes soil, water, fertilizer, nature character (temperature, humidity etc.) and industry produced agriculture materials. Those resources are evaluated in several evaluation models. The brief models are:

Country vegetable market evaluation

Country commercial environment evaluation

Agriculture industry development evaluation

Village affair process

Chinese farmers are group of people who lack agriculture and computer skills. Simple end user skills will help user use system in a short time. That is so called "Putting Technique upper, providing service lower". Most of the system functions are implemented on the server ends, end user just use a internet browser visit all the functions supported by the server without any plug-in or add-on component.

\subsection{Multi-layer Structure}

eARISP was designed as a 3 layer system. Each layer could maintain and expend easily. Database support subsystem is the base layer. All of the database management 
and maintaining are based on the lower layer components. The middle layer contains GIS model and general reuse models, such as transaction process. the middle layer can expended by adding software in future. The upper layer is affair process interface and all of the manager interface. Figure 2 shows software structure.

GIS is a complex but important technique in eARISP, so do other common, reusable transaction process models. All of those were designed as middleware. Middleware connect base layer and application and user interface. It provides system stability and expendability.

\section{System Implementation}

Most popular network server operate system are Microsoft Windows Server 2003 and various Linux server editions. The first edition of eARISP was implemented under support of Microsoft Windows Server 2003 and Microsoft .net development system and MySQL database system. Web server and GIS server work together. An agriculture data integrate networks works as a supplement system to collect agriculture data from various agriculture concerned department.

eARISP was built into two main interface, front interface and management interface. Front interface faces to end user, management user of town and county and adviser user who maintain the knowledgebase and answer questions. Management interface faces to super user and some user who has duty to maintain the system. Most GIS graph process and data maintain on the desktop software and store data to database in management interface.

\section{Discussion}

Agriculture industrialization information support system is a complex subject and different development stage have different requirement. The platform we setup during the project period is just a beginning and a test. GIS technique application and agriculture knowledge effective manage are developing. This paper try to describe whole system structure, technique detail are ignored. With eARISP application spreading, improvement will made and apply to the new edition.

\section{References}

[1] Bernstein, P.A., Newcomer, E.: Principles of Transaction Processing, 2nd edn. Elsevier Inc., Burlington (2009)

[2] Simsion, G.C., Witt, G.C.: Data Modeling Essentials, 3rd edn. Elsevier Inc., San Francisco (2005)

[3] Wu, H.-r., Wang, Z.-1., Yang, B.-z., Sun, X.: Research and Implementation on Platform for Electronic Agriculture with Web Application Server. Journal, Microcomputer Development 14(1), 75-78 (2004)

[4] Xu, Y., Qi, W.-H., Xie, G.-D., Zhang, Y.-S.: “The Factor-Energy Evaluation Model Of Agricultural Natural Resources Utilization Efficiency And Its Application. Journal, Resources Science 24(3), 86-91 (2002) 